\title{
EFFECT ON AIR QUALITY OF PUNE DUE TO COVID -19

\author{
Roma Srivastava ${ }^{1}$, Paritosh Srivastava ${ }^{2}$ \\ E-Mail Id: romasrivastava@gmail.com ${ }^{1}$, paritosh.srivastava@ niu.edu.in ${ }^{2}$ \\ Noida International University, Greater Noida, India
}

Abstract-Due to the covid-19 pandemic, the lockdown has been implemented throughout India since mid-march 2020. This paper discusses the comparative analysis of air quality for two consecutive years 2019 and 2020 in the Pune region with data obtained from the Central Pollution Control Board (CPCB), and real-time verification, with a survey of over 100 families across Pune. This paper also determines and crosschecks possible sources for predominant pollutants during the lockdown period along with the meteorological factors. Due to restriction of activities during lockdown such as industrial, transportation, commercial, etc, a significant average reduction in pollutants was observed. During lockdown (20 March-20 May), calculations with observed data indicate 57\% reduction in PM2.5, 46\% reduction in PM10, 25\% reduction in $\mathrm{NO}_{2}, 49 \%$ reduction in ozone, $10-15 \%$ reduction in $\mathrm{SO}_{2}$ and $42 \%$ reduction in AQI. The preceding figures signify the city received better air quality after decades. However, a significant hike was observed in CO. The analysis shows that strict lockdown can not only keep people safe from covid but also has the potential to heal the environment.

Keywords: AQI, CO, Covid-19, $\mathrm{NO}_{2}, \mathrm{O}_{3}$, Particulate matter, $\mathrm{SO}_{2}$.

\section{INTRODUCTION}

Air pollution is globally the most significant issue impacting the environment. Greenhouse gases and other emissions adversely affect public health with the observed increase in cases of asthma, cardiovascular, allergies, and respiratory problems [1]. Mostly anthropogenic activities such as industrial processes, transportation, burning of fossil fuel and construction are the primary sources of emitting air pollutants such as PM2.5, PM10, $\mathrm{NO}_{2}, \mathrm{SO}_{2}, \mathrm{CO}$, Ozone and other compounds formed in the atmosphere as a result of photochemical processes [2,3]. The indoor air pollutants emitted from activities such as cooking, heating, etc., also contribute to deteriorating air quality. As a result, a large number of urban residents face significantly high health risks [4]. India is one of the countries, which is at higher risk because of continuously increasing pollution. The increase in pollution is caused due to urbanization, industrialization, and population growth. Additionally, meteorological parameters such as temperature, relative humidity (RH), and wind also influence the air quality [5]. As per research, PM2.5 and PM10 concentrations are higher during the dry season. Whereas during the monsoon season, when the precipitation rate is high, concentrations reduce. The main source of $\mathrm{SO}_{2}$ emission in the atmosphere is the power generation using coal-based fuel, whereas the sources of $\mathrm{NO} 2$ emissions are vehicular and industrial activities [6, 7]. The objective of this study is to investigate the average concentration of air pollutants such as PM2.5, PM10, $\mathrm{NO}_{2}, \mathrm{SO}_{2}, \mathrm{CO}$, Ozone along with the air quality index (AQI) while all human activities are restricted due to Covid-19, the reduction of pollutants in percentage w.r.t 2019, and real-time verification of air quality and health by a survey done across Pune.

\section{RESEARCH METHODOLOGY AND DATA SOURCES}

The purpose of the study is to investigate the effects of lockdown on air quality and health. The study is restricted to the region of Pune city. The time period of study is between mid-March to mid-May in 2020. The study compares data from the time period to that of 2019. From the CPCB website, real-time 24-hrs average concentrations of five criteria air pollutants (PM2.5, PM10, $\mathrm{NO}_{2}, \mathrm{SO}_{2}$ ) and 8-hrs continuous concentration of $\mathrm{CO}$ and Ozone were obtained along with the Air quality index (AQI). Meteorological parameters such as wind, temperature, and relative humidity ( $\mathrm{RH}$ ) were obtained from an online weather site (detail given below). In this paper, the obtained data are statistically analyzed using secondary data (Pollutant concentrations, Temperature, and RH) and by qualitative surveys using questionnaires. The general questionnaire was prepared to analyze the impact of the restriction of local activities on improvement in indoor and outdoor air quality felt by individuals. Additionally, the questionnaire gathered responses on the biggest causes of deteriorating surroundings air before and during the lockdown. The analysis of pollutant conditions is verified by a real-time survey conducted on parameters related to the impact on health during the lockdown period. The survey also indicated that during the lockdown period, for the first time in decades, people felt very fresh and good quality air. Even persons staying near densely populated areas and having a persistent health history, such as asthma, allergy, etc. felt some relief during the lockdown. At the same time survey results indicate, cooking, heating, and uses of electronic gadgets were significantly higher which can cause increased indoor pollutants, this was verified by data obtained.

\section{RESULT AND DISCUSSIONS}

3.1 Nitrogen dioxide $\left(\mathrm{NO}_{2}\right)$

A $25 \%$ reduction in the average concentration of $\mathrm{NO}_{2}$ has been recorded during the lockdown period (20 March -20 May) as compared to last year at the same time in the Pune region as per CPCB data shown in Figure 3.1. The main source of $\mathrm{NO}_{2}$ emissions is economic activities, transport restriction, industrial and energy sectors. A positive 
ICACCG2020 30-31 July, 2020, Ansal University, Gurgaon, India

International Journal of Technical Research \& Science (Special Issue) ISSN No.:2454-2024 (online)

correlation of pollutants, including $\mathrm{NO}_{2}, \mathrm{CO}, \mathrm{PM} 2.5$, PM10, and $\mathrm{O}_{3}$ with temperature and relative humidity is discussed in previous studies along with a negative correlation for $\mathrm{SO}_{2}$ [8]. As per data analyzed, temperature and relative humidity are less this year as compared to 2019 shown in Fig. 3.2, which clearly could be a supporting cause for the decrease in the percentage of pollutants in 2020. The survey also clearly indicated more than $90 \%$ of people used vehicles only once or twice during the lockdown as compared to daily vehicle usage before, which also counted in reducing $\mathrm{NO}_{2}$ emissions.

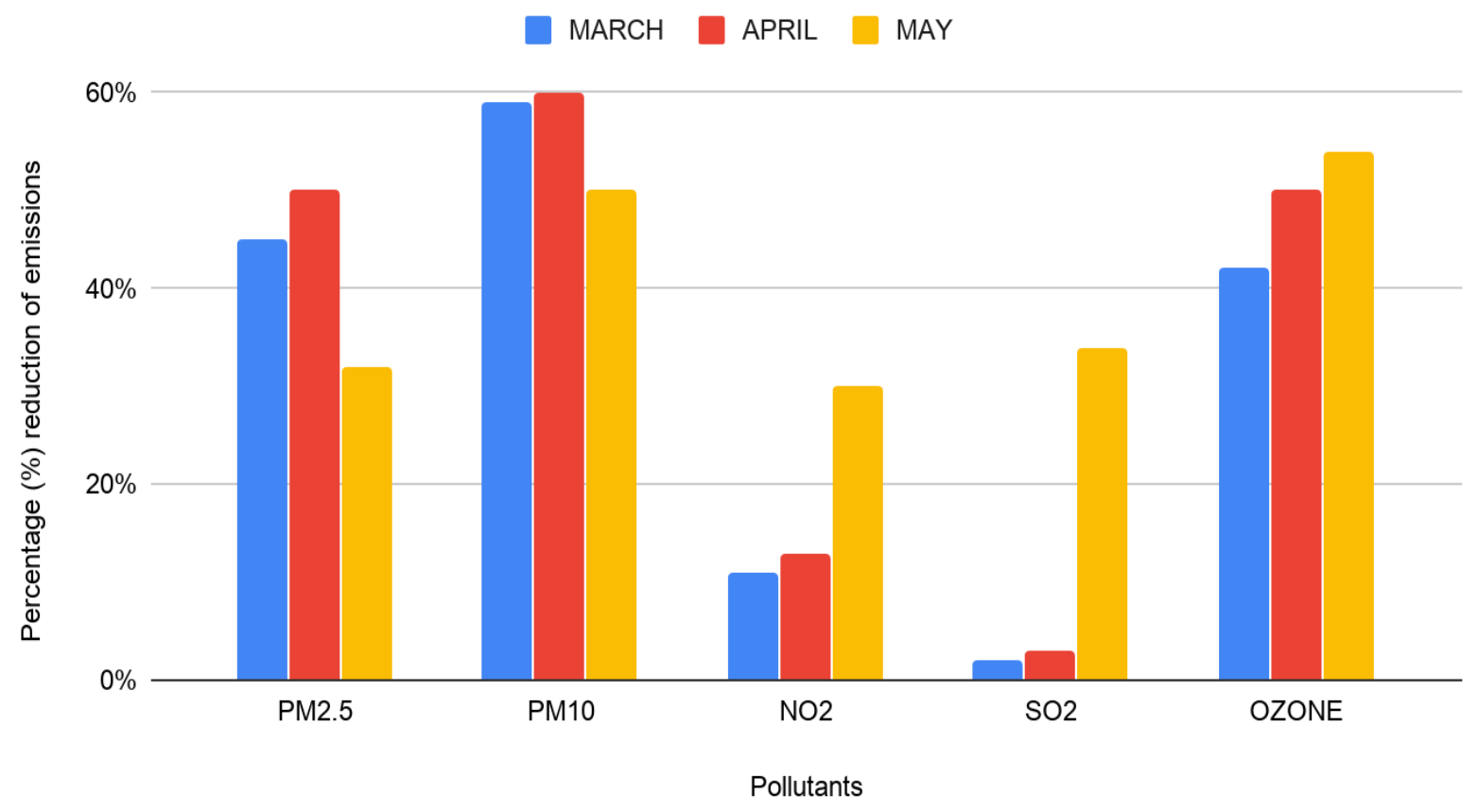

Fig. 3.1 Percentage Reduction (\%) in Emissions in 2020 as Compared to 2019

\subsection{Particulate Matter}

PM2.5 was found to be the dominant pollutant in 2019 during analyzing data obtained by CPCB due to excessive transportation activity which is one of the primary sources of PM2.5(size less than $2.5 \mathrm{~mm}$ ). In 2020, the greatest fall was recorded in PM2.5 during the last two weeks of March during the lockdown, which was around 45\%. In April month it was increased to $50 \%$ due to complete restriction of manmade activities, while in May month (till 20th May) again slight fall was recorded in percentage reduction which is $32 \%$, this might be attributed to some stuck people transport movement ordered by the government for a few days and change in meteorological conditions (min and max. Temperature started to increase as the onset of summer.) but It was also analyzed in a survey that during lockdown people only used four wheelers for essentials which also contributes to the percentage of PM2.5 and PM10. On the other hand, the same trend has been seen for PM10 too in March, April and May as compared to last year, which is 59\%, 60\% and 50\%, respectively clearly shown in the reduction Figure 3.1. During the lockdown period (20 March- 20 May), the 24-hour average concentrations of PM2.5 and PM10 were $41 \mu \mathrm{g} / \mathrm{m}^{3}$ and $36 \mu \mathrm{g} / \mathrm{m}^{3}$ respectively.

\subsection{Sulfur Dioxide $\left(\mathrm{SO}_{2}\right)$}

There is a slightly less effect of lockdown seen in the reduction of $\mathrm{SO}_{2}$ emission. As $70 \%$ of total $\mathrm{SO}_{2}$ is emitted from coal-based power stations which were fully operational during the lockdown, the rest comes from other activities like vehicles, industrial and biomass burning [6]. In Pune low sulfur content fuels are already used in vehicles that contribute the lowest $\mathrm{SO}_{2}$, so restricting vehicular movements do not add a steep reduction in 8-hour average $\mathrm{SO}_{2}$ concentration. A negative correlation between $\mathrm{SO}_{2}$ and temperature and relative humidity also stated the result. The average percentage of emission reduction was recorded $15-20 \%$ during lockdown till 20 May as compared to last year (shown above Figure 3.1) and the 8-hour average $\mathrm{SO}_{2}$ concentration was $30 \mu \mathrm{g} / \mathrm{m}^{3}$.

\subsection{Carbon Monoxide (CO)}

Carbon monoxide was calculated as the predominant pollutant during the lockdown period. The emission average concentration of CO (8-hrs) was quite high, i.e. $67 \mu \mathrm{g} / \mathrm{m}^{3}$ in March month as compared to last year, which was 34 $\mu \mathrm{g} / \mathrm{m}^{3}$ while a little less during the months of April and May shown in Table-3.1 and the average increase in the percentage of $\mathrm{CO}$ concentration as compared to last year was $42 \%$ shown in Fig. 3.2. This may be due to the unauthorized use of diesel generators and local burning of garbage which emits $\mathrm{CO}$, during lockdown when nothing is operational this could be the reason for such a hike. Low temperature and positive linear correlations with RH [9] 
ICACCG2020 30-31 July, 2020, Ansal University, Gurgaon, India

International Journal of Technical Research \& Science (Special Issue) ISSN No.:2454-2024 (online)

also could be one of the factors, along with emitted $\mathrm{CO}$ from indoor sources (mainly cooking and heating) which is also substantially high indicated in the survey across the city. Our findings are supported by multiple case studies done during the lockdowns in few cities of India. Although the CO concentration was below acceptable limits, it remained the predominant pollutant among all six criteria pollutants.

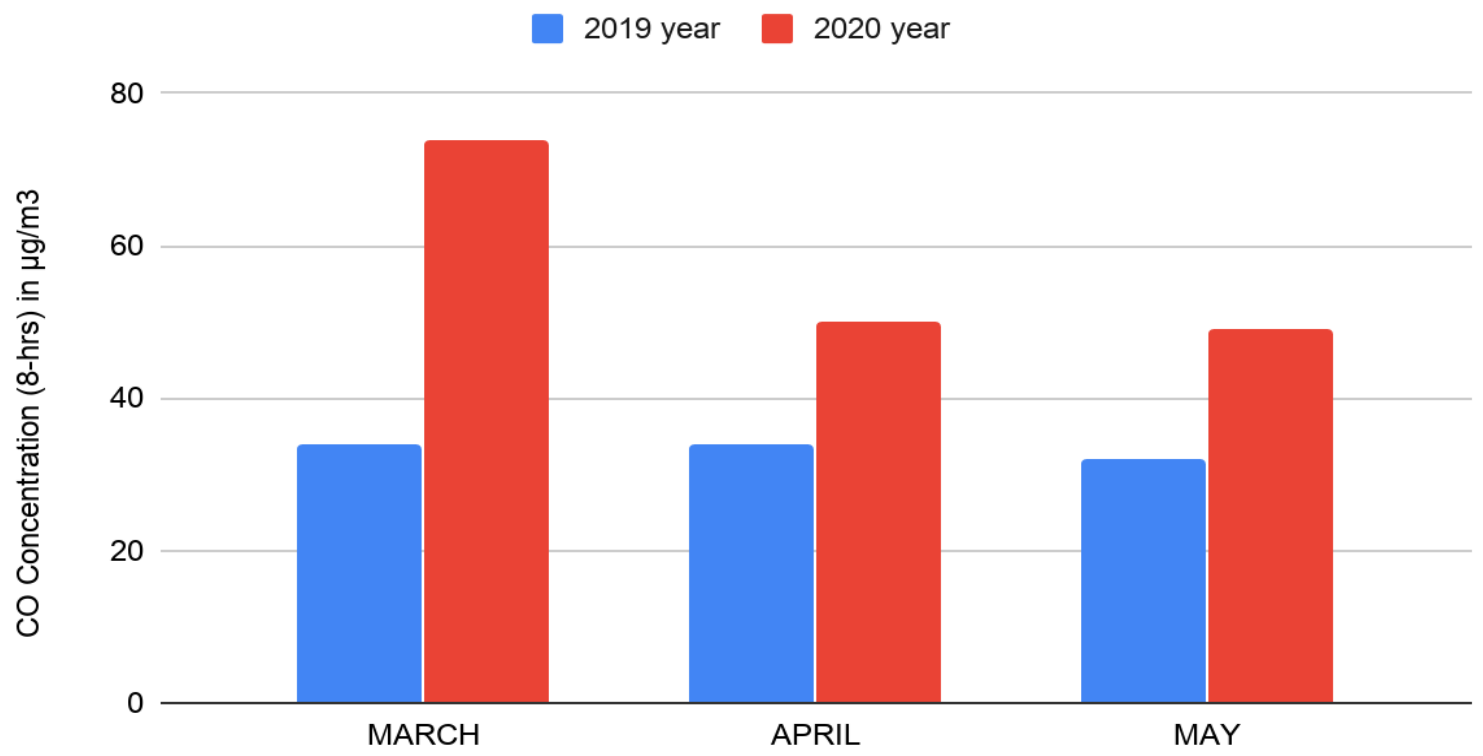

Lockdown Months

Fig. 3.2 Carbon Monoxide (CO) The Average Concentration $\left(\mu \mathrm{g} / \mathrm{m}^{3}\right)$

Table-3.1 Criteria Pollutants Average Concentrations and AQI in the year 2019 \& 2020

\begin{tabular}{|c|c|c|c|c|c|c|}
\hline & \multicolumn{2}{|c|}{ March } & \multicolumn{2}{|c|}{ April } & \multicolumn{2}{|c|}{ May } \\
\hline Pollutants & $\begin{array}{l}\text { Year } \\
2019\end{array}$ & $\begin{array}{l}\text { Year } \\
2020\end{array}$ & $\begin{array}{l}\text { Year } \\
2019\end{array}$ & $\begin{array}{l}\text { Year } \\
2020\end{array}$ & $\begin{array}{l}\text { Year } \\
2019\end{array}$ & $\begin{array}{l}\text { Year } \\
2020\end{array}$ \\
\hline $\begin{array}{l}\text { PM2.5 }(24-\mathrm{hrs}) \mu \mathrm{g} / \mathrm{m}^{3} \\
\text { (NAAQS permissible limit PM2.5 }=60 \mu \mathrm{g} / \mathrm{m}^{3} \text { ) }\end{array}$ & 127 & 42 & 89 & 43 & 87 & 44 \\
\hline $\begin{array}{l}\text { PM10 }(24-\mathrm{hrs}) \mu \mathrm{g} / \mathrm{m}^{3} \\
\text { (NAAQS permissible limit PM10 }=100 \mu \mathrm{g} / \mathrm{m}^{3} \text { ) }\end{array}$ & 131 & 41 & 92 & 36 & 81 & 33 \\
\hline $\begin{array}{l}\mathrm{NO}_{2}(24-\mathrm{hrs}) \mu \mathrm{g} / \mathrm{m}^{3} \\
\text { ( NAAQS permissible limit of } \mathrm{NO}_{2}=80 \mu \mathrm{g} / \mathrm{m}^{3} \text { ) }\end{array}$ & 17 & 13 & 15 & 13 & 20 & 14 \\
\hline $\begin{array}{l}\mathrm{SO}_{2}(24-\mathrm{hrs}) \mu \mathrm{g} / \mathrm{m}^{3} \\
\text { ( NAAQS permissible limit of } \mathrm{SO}_{2}=80 \mu \mathrm{g} / \mathrm{m}^{3} \text { ) }\end{array}$ & 34 & 31 & 31 & 30 & 41 & 27 \\
\hline $\begin{array}{l}\mathrm{CO}(8-\mathrm{hrs}) \mu \mathrm{g} / \mathrm{m}^{3} \\
\text { ( NAAQS permissible limit of } \mathrm{CO}=02 \mathrm{mg} / \mathrm{m}^{3} \text { ) }\end{array}$ & 34 & 67 & 34 & 50 & 32 & 49 \\
\hline $\begin{array}{l}\text { OZONE }(8-\mathrm{hrs}) \mu \mathrm{g} / \mathrm{m}^{3} \\
\text { ( NAAQS permissible limit of } \mathrm{O}_{3}=100 \mu \mathrm{g} / \mathrm{m}^{3} \text { ) }\end{array}$ & 45 & 22 & 44 & 21 & 46 & 21 \\
\hline AQI (Air Quality Index) & 139 & 65 & 102 & 53 & 87 & 52 \\
\hline
\end{tabular}

\subsection{Ozone}

Surface ozone can cause serious health problems and play a role in degrading the environment as a greenhouse gas. It is produced by complex reactions between NOx and VOCs [10]. High RH is attributed due to a significant removal of NOx concentration in the atmosphere due to restricting all emission sources, thus increasing RH (Fig. 3.4) and decreasing $\mathrm{NO}_{2}$ concentrations (Table-3.1) during lockdown could be a reason for the reduction of removal of percentage ozone concentration [11] by 40-50\% this year as compared to 2019 shown in Fig 3.1.

DOI Number: https://doi.org/10.30780/specialissue-ICACCG2020/002

pg. 11

Paper Id: IJTRS-ICACCG2020-002

@ 2017, IJTRS All Right Reserved, www.ijtrs.com 

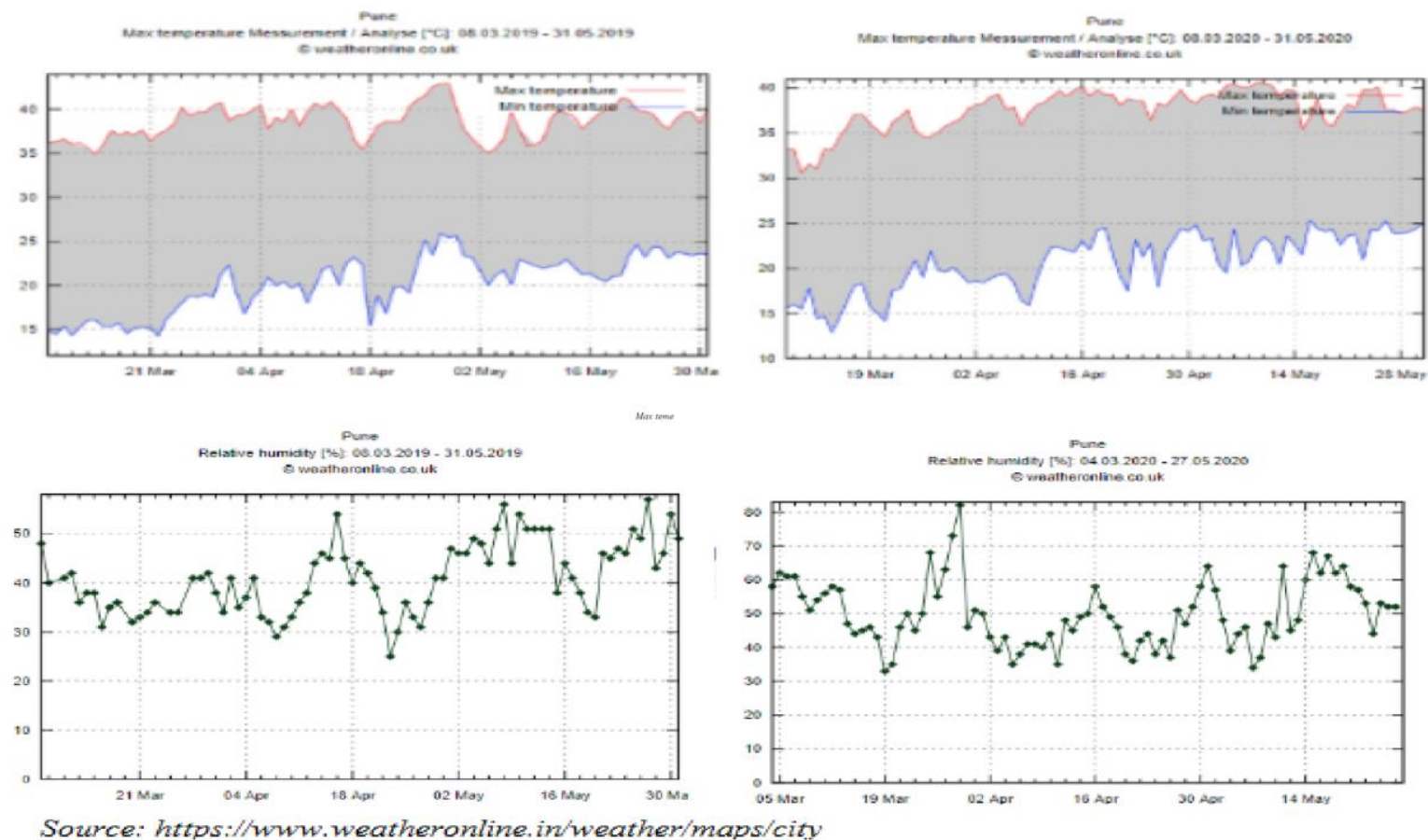

Source: https:/www.weatheronline in/weather/maps/city

Fig. 3.3 Temperature and Relative Humidity Variation in 2019 \& 2020

\subsection{Air quality index}

The daily quality of air is measured in terms of air quality index, which is calculated considering the criteria air pollutants, ammonia $\left(\mathrm{NH}_{3}\right)$, and lead $(\mathrm{Pb})$. It is divided into six categories. These categories are; good (0-50), satisfactory (51-100), moderate (101-200), poor (201-300), very poor (301-400) and severe (401-500) [12]. The air quality index for the first time in code green means between good to satisfactory categories due to the lockdown period in most of the cities of India. During the lockdown period, the AQI was recorded at the lowest level after decades continuously for 8 weeks. The calculated average percentage reduction of AQI was approximately $50 \%$ as compared to 2019 which is also clearly shown in Fig 3.4 and the average value was 56 given above in Table-3.1.

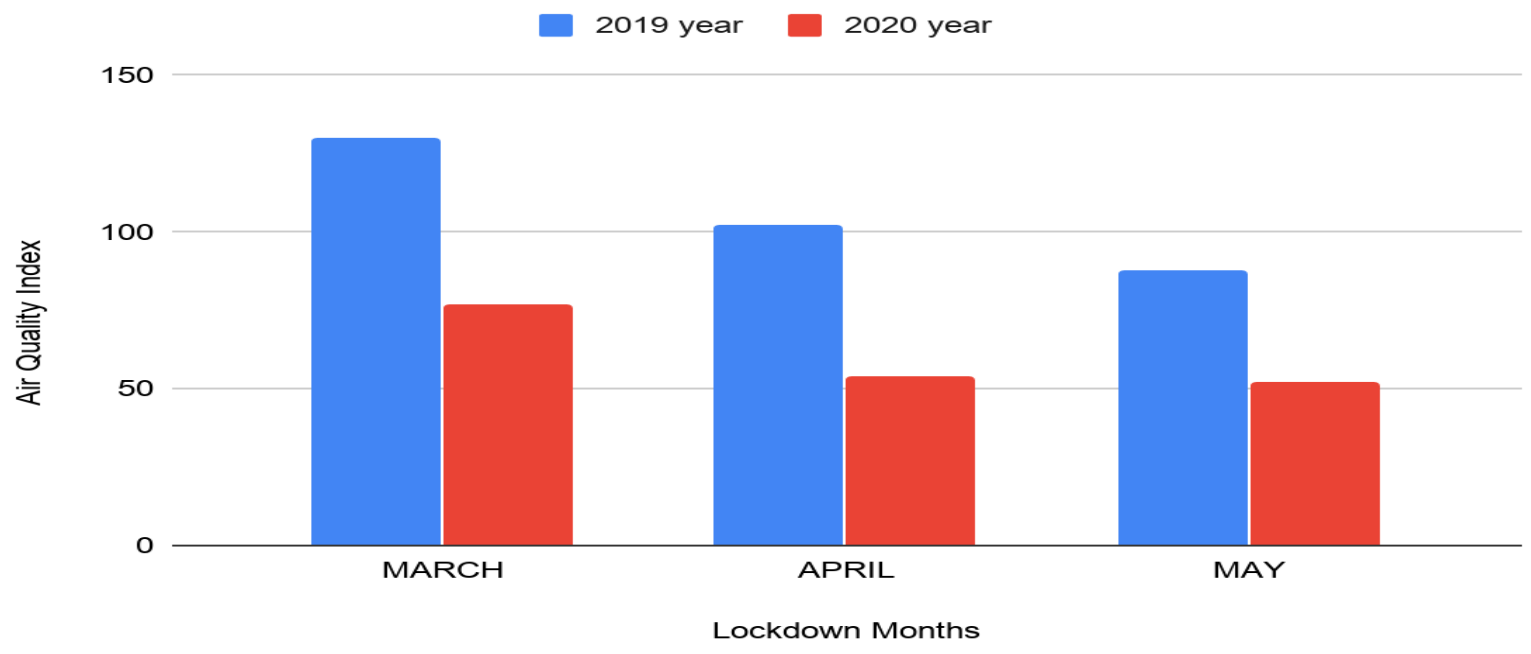

Fig. 3.4 Air Quality Index (AQI) Comparison in 2019 \& 2020

\section{CONCLUSION}

These observations are very helpful to understand the lowest limit of all criteria pollutants during lockdown while all activities are restricted, the results are very promising and give hope to reduce pollutant concentrations to some extent by taking a few precautions in the future. PM2.5, PM10, $\mathrm{NO}_{2}$, and ozone concentrations are at their lowest level in the last few decades, while the variation in $\mathrm{SO}_{2}$ concentration is not very significant. The emission of $\mathrm{CO}$ is noticed significantly high during the lockdown period, indicating indoor emission contributed to some extent. The average maximum temperature was recorded approximately 2 degrees lower as compared to 2019 and relative 
ICACCG2020 30-31 July, 2020, Ansal University, Gurgaon, India

International Journal of Technical Research \& Science (Special Issue) ISSN No.:2454-2024 (online)

humidity (RH) was increased in 2020 (Fig. 3.4) which could be a possible outcome of halting maximum pollutants generating anthropogenic activities thus a reduction in pollutant emissions. The Survey also verified the people's satisfaction with the air quality in the city for the very first time.

\section{DATA SOURCES WEBSITE}

Criteria Pollutants concentration: https://app.cpcbccr.com/AQI_India

Meteorological parameters: https://www.weatheronline.in/weather/maps/city

\section{REFERENCES}

[1] Azad A.Kand T. Kitada, Characteristics of the Air Pollution in the City of Dhaka, Bangladesh in Winter (1998), Atmospheric Environment, 32, No.11, P.1991-2005, 1998.

[2] Bilkis A. Begum, Philip K, Air Quality in Dhaka Bangladesh over Two Decades: Impacts of Policy on Air Quality, Volume 18, Issue 7, July 2018.

[3] Manoli E., Voutsa D., Samara C, 2002. Chemical characterization and source identification/apportionment of fine and coarse air particles in Thessaloniki, Greece. Atmos. Environ. 2002; 36:949-961. doi: 10.1016/S13522310(01)00486-1.

[4] Helmut Mayer, Air pollution in cities, Atmospheric Environment, Volume 33, Issues 24-25, October 1999, Pages 4029-4037.

[5] Zhang. H, Yungang Wang, Jianlin Hu, Qi Ying, Xiao-Ming Hu, Relationships between meteorological parameters and criteria air pollutants in three megacities in China, Environmental Research, Volume 140, July 2015, Pages 242-254.

[6] Chen, T.-M.; Kuschner, W.G.; Gokhale, J.; Shofer, S. Outdoor Air Pollution: Nitrogen Dioxide, Sulfur Dioxide, and Carbon Monoxide Health Effects. Am. J. Med. Sci. 2007,333, 249-256.

[7] Sivakumaran Sivaraman, Air Pollution sources, pollutants and mitigation measures, December 2014.

[8] Kayes. I, S.A. Shahriar, K. Hasan, M. Akhter, M.M. Kabir, M.A. Salam, The relationships between meteorological parameters and air pollutants in an urban environment. Global J. Environ. Sci. Manage. 5(3): 265-278, Summer 2019.

[9] Xiaobing Pang, Marvin D. Shaw, Stefan Gillot, Alastair C. Lewis, The impacts of water vapor and copollutants on the performance of electrochemical gas sensors used for air quality monitoring, Sensors and Actuators B: Chemical, Volume 266, 1 August 2018, Pages 674-684.

[10] Chan L.Y., C.Y. Chan, Y. Qin, Surface ozone pattern in Hong Kong, Journal of Applied Meteorology, 37 (1998), pp. 1153-1165.

[11] Vaida Valuntaitè, Vaida Šerevičienè, Raselè Girgždienè, Dainius Paliulis, Relative Humidity and Temperature Impact to Ozone and Nitrogen Oxides Removal Rate in the Experimental Chamber, Journal of Environmental Engineering and Landscape Management 20(1):35-41 • March 2012.

[12] Air Quality Index.pdf - India Environment Portal, available from www.indiaenvironmentportal.org.in. 